\title{
ERp57-small interfering RNA silencing can enhance the sensitivity of drug-resistant human ovarian cancer cells to paclitaxel
}

\author{
SHUO LI ${ }^{1}$, XIAOYUN ZHAO ${ }^{2}$, SHIJIE CHANG $^{3}$, YANQIU LI $^{1}$, MIN GUO $^{1}$ and YIFU GUAN ${ }^{1}$ \\ ${ }^{1}$ Department of Biochemistry and Molecular Biology, China Medical University, Shenyang, Liaoning 110122; \\ ${ }^{2}$ Department of Microbiology and Cell Biology, Shenyang Pharmaceutical University, Shenyang, Liaoning 110016; \\ ${ }^{3}$ Department of Biomedical Engineering, China Medical University, Shenyang, Liaoning 110122, P.R. China
}

Received January 5, 2018; Accepted October 8, 2018

DOI: $10.3892 /$ ijo.2018.4628

\begin{abstract}
ERp57 has been identified to be associated with the chemoresistance of human ovarian cancer. However, its biological roles in the chemoresistance phenotype remain unclear. In the present study, the association of ERp57 with paclitaxel-resistant cellular behavior was investigated and the sensitivity enhancement of chemoresistant human ovarian cancer cells to paclitaxel was examined using ERp57-small interfering (si)RNA silencing. Cell viability, cell proliferation, cell apoptosis and cell migration were detected using an MTT assay, clonogenic assay, flow cytometry analysis and transwell assay. Furthermore, mRNA expression levels of ERp57 and protein expression levels of ERp57, STAT3, phosphorylated STAT3, PCNA, nucelolin, TUBB3, P-gp, vimentin, Bcl-2, Bax, Bcl-xl, p53, MMP1, MMP2 and MMP9 of paclitaxel-sensitive human SKOV3 ovarian cancer cells were compared with paclitaxel-resistant counterpart SKOV3/tax using the real-time PCR and western blot analysis. ERp57 was highly expressed in the paclitaxel-resistant SKOV3/tax cells, and experimental results concluded that the paclitaxel-resistance phenotype was due primarily to the activation of the STAT3 signaling pathway. ERp57 overexpression by lentiviral particle infection decreased the sensitivity of SKOV3 cells to paclitaxel. Furthermore, ERp57-siRNA silencing restored paclitaxel sensitivity of SKOV3/tax cells. Notably, the $\mathrm{IC}_{50}$ value of ERp57-siRNA silenced SKOV3/tax cells was reduced to the original level
\end{abstract}

Correspondence to: Professor Yifu Guan, Department of Biochemistry and Molecular Biology, China Medical University, 77 Puhe Road, Shenyang, Liaoning 110122, P.R. China E-mail: yfguan@cmu.edu.cn

Abbreviations: si, small interfering; STAT3, signal transducer and activator of transcription 3; p-, phospho; PCNA, proliferating cell nuclear antigen; P-gp, P-glycoprotein; TUBB3, class III $\beta$-tubulin; Bcl-2, B-cell lymphoma-2; Bax, Bcl-2-associated X protein; Bcl-xl, B-cell lymphoma-extra large; MMP, matrix metalloproteinase

Key words: ERp57, ovarian cancer, chemoresistance, STAT3, bioinformatics and colony survival was significantly decreased in comparison with that of SKOV3/tax cells. Additionally, co-treatment of ERp57-siRNA silencing and paclitaxel could inhibit the STAT3 signaling pathway and downregulate the expression levels of downstream proteins. Notably, ERp57-siRNA and $100 \mathrm{nM}$ paclitaxel co-treatment downregulated Bcl-2, Bcl-xl, MMP2, MMP9, TUBB3 and P-gp expression levels and upregulated the expression of Bax protein. Furthermore, co-treatment promoted change of the isoform of p53 to p53/p47. Bioinformatics analyses supported the experimental observations that ERp57 was associated with drug resistance in ovarian cancer. The present study implies that ERp57 is a potential therapeutic target for the treatment of paclitaxel-resistant human ovarian cancer.

\section{Introduction}

Out of the various types of gynecological malignant tumors, ovarian cancer is considered the leading cause of fatality among women worldwide (1). This is a result of two factors. Firstly, lack of reliable and accurate methods for early diagnosis results in the confirmation of the late-stage ovarian cancer in $>70 \%$ of patients $(2,3)$. Secondly, the multidrug resistance (MDR) phenotype can develop post-chemotherapy treatment, which typically results in a high recurrence rate $(>50 \%)$ and poor prognosis for these patients (4).

A great effort has been made to understand the molecular mechanisms of the MDR phenotype, and several models have been proposed, including the upregulated expression of MDR proteins (which efflux the anti-cancer agents out of cancer cells), the evasion of cell apoptosis through the overexpression of anti-apoptotic proteins, the increased recovery capability of the DNA-damage repairing system and the accelerated metabolism of anti-cancer agents (5-7). Various proteins affect cell growth and cytokine signaling pathways, and cell cycle behavior also serves important roles in the development of the MDR phenotype (8-10). Since MDR has become a more serious concern in the clinic, the development of novel strategies to overcome the MDR phenotype is of importance.

ERp57 was first reported to be associated with the chemotherapy resistance of ovarian cancer by Bernardini et al (11) in 2005. Their array comparative genomic hybridization and microarray expression profiling result identified a novel class of genes associated with in vivo drug 
response in patients with. ovarian cancer. ERp57 has been indicated to form a nuclear complex that is associated with resistance to DNA conformation-altering chemotherapeutic agents in in vitro systems. Cicchillitti et al (12) used a comparative proteomic approach to analyze the paclitaxel sensitivity of A2780 epithelial ovarian cancer cells and identified that ERp57 is a protein that is altered in paclitaxel-resistant cell lines when compared with paclitaxel-sensitive cell lines (12). ERp57 interacts with class III $\beta$-tubulin (TUBB3) in paclitaxel-resistance ovarian cells, and this ERp57/TUBB3 interaction occurs in a novel location of the cytoskeleton rather than the nuclear compartment (12). These results indicate that ERp57 may serve an important role in the chemoresistance of ovarian cancer by modulating the attachment of microtubules to chromosomes following paclitaxel treatment through its interaction with TUBB3. However, the biological roles of ERp57 in the chemoresistance of ovarian cancer remain unknown, and no studies have explored the effects of ERp57 downregulation on the improvement of the paclitaxel sensitivity of chemoresistant ovarian cancer.

In the present study, the expression levels of ERp57 were compared in SKOV3 ovarian cancer cells and paclitaxel-resistant SKOV3/tax cells. The small interfering (si)RNA approach was used to inhibit the expression of ERp57. Furthermore, the biological effects of ERp57-siRNA silencing on the possible MDR reversal of SKOV3/tax cells were examined. Bioinformatics analysis was also performed to identify the biological processes and pathways associated with ERp57 and chemoresistant ovarian cancer.

\section{Materials and methods}

Chemicals and reagents. All chemicals were obtained from Shenyang Sinopharm Group (Shenyang, China) unless otherwise stated. ERp57 inhibitor DNTB was obtained from Sigma-Aldrich; Merck KGaA (Darmstadt, Germany).

Cell lines and cell cultures. Human epithelial ovarian cancer cells SKOV3 were purchased from Beijing Shijitan Hospital (Beijing, China). Cells were cultured in RPMI-1640 medium (Hyclone; GE Heathcare Life Sciences, Logan, UT, USA) supplemented with L-glutamine and $10 \%$ fetal bovine serum (TBD, Tianjin, China) in a humidified incubator $\left(5 \% \mathrm{CO}_{2}\right.$ at $\left.37^{\circ} \mathrm{C}\right)$. Cell lines grew in a monolayer and were passaged when cultures were $70-80 \%$ confluent.

Establishment of SKOV3/tax cells. The paclitaxel-resistant SKOV3 (SKOV3/tax) were prepared following a standard stepwise selection procedure. SKOV3 cells were cultured in RPMI-1640 medium containing paclitaxel at a concentration of $0.1 \mathrm{nM}$ for $24 \mathrm{~h}$. Cells that survived were selected for the next survival selection step using a higher paclitaxel concentration. This cell culture process was repeated for several steps with an increment of $0.5 \mathrm{nM}$ at each step until all cells could survive at the paclitaxel concentration of $10 \mathrm{nM}$. The survived cells were able to maintain the paclitaxel-resistance phenotype in the absence of the selection pressure and were named SKOV3/tax (13).

Giemsa staining. SKOV3 and SKOV3/tax cells were seeded on 6 -well plates at the cell density of $2 \times 10^{6}$ cells $/ \mathrm{ml}$. Following
$24 \mathrm{~h}$ of incubation, cells were washed with PBS 3 times and fixed with methanol for $30 \mathrm{~min}$ at room temperature. Subsequently, cells were stained with Giemsa dye (Beyotime Institute of Biotechnology, Shanghai, China) for $15 \mathrm{~min}$ at room temperature. Cells were washed with PBS once and with deionized water three times. Once they were dried, SKOV3 and SKOV3/tax cells were examined under an optic microscope (at magnifications, x100 and x200, respectively).

Cell viability analysis. SKOV3 and SKOV3/tax cells were seeded on 96 -well plates at a cell density of $5 \times 10^{3}$ cells/well or on 6-well plates at the cell density of $1 \times 10^{6}$ cells/well, respectively. Following $24 \mathrm{~h}$ of incubation, cell culture medium (RPMI-1640) was aspirated and replaced with fresh culture medium containing different concentrations of paclitaxel $(0.01,0.1,1.0,10,100$ and $1,000 \mathrm{nM})$. Following 48 or $72 \mathrm{~h}$ incubation, cell viability was assessed using MTT assay. Each well was aspirated and incubated with $5 \mathrm{mg} / \mathrm{ml} \mathrm{MTT}$ reagent (in 0.01 M PBS, pH 7.4). $4 \mathrm{~h}$ later, extraction buffer was added to each well to resolve the MTT crystals and the optic absorbance at $570 \mathrm{~nm}$ was measured using an Infinite M200 PRO multiplate reader (Tecan Group Ltd., Männedorf, Switzerland). Cell viability was calculated based on the optic absorbance. Untreated cells were used as a blank control (considered as $100 \%$ viable). $\mathrm{IC}_{50}$ values were estimated from concentration-viability curves.

ERp57 overexpression induced by lentiviral particle infection. Lentiviruses carrying ERp57 expression vectors were obtained from GeneChem (Shanghai, China). ERp57 overexpression was conducted according to the company's instructions. Briefly, cells $\left(0.5 \times 10^{5}\right.$ cells/well $)$ were seeded in a 12 -well plate and treated with lentiviral particles to establish ERp57 overexpression [40 $\mu \mathrm{l}$ polybrene and $2.5 \mu \mathrm{l} /$ well containing $1 \times 10^{8}$ infectious units (IFU) of ERp57 overexpression virus] and scramble control (40 $\mu \mathrm{l}$ polybrene and $2.5 \mu \mathrm{l} /$ well containing $1 \times 10^{8}$ IFU scramble virus) groups. The blank group consisted of SKOV3 cells without lentiviruses transfection. Fresh medium (RPMI-1640) without polybrene was placed on each infected well following $24 \mathrm{~h}$ of incubation.

Silencing ERp57 with siRNA. ERp57-siRNA was used to target the ERp57 gene (nucleotide sequence, 5'-GGGCAAG GACUUACUUAUU-3'). For comparison, a random nucleotide sequence of 5'-UUCUCCGAACGUGUCACGU-3' was used as a negative control (NC-siRNA). Transfection of NC-siRNA and ERp57-siRNA was carried out, respectively, in a final concentration of $50 \mathrm{nM}$ using Lipofectamine 2000 (Invitrogen; Thermo Fisher Scientific, Inc., Waltham, MA, USA) according to the manufacturer's protocol. The blank group was SKOV3/tax cells without siRNA transfection. After $48 \mathrm{~h}$ of incubation, the transfected cells were collected for cell apoptosis analysis. Total mRNAs and proteins of these cells were isolated for reverse transcription-quantitative polymerase chain reaction (RT-qPCR) and western blot analysis, respectively.

Western blot analysis. SKOV3/tax cells were treated with ERp57-siRNA for $48 \mathrm{~h}$, followed by $10 \mathrm{nM}$ paclitaxel (the dosage commonly used for treatment of SKOV3 cells) for $48 \mathrm{~h}$ and $100 \mathrm{nM}$ paclitaxel (the concentration near the $\mathrm{IC}_{50}$ value 
of SKOV3/tax cells) for $48 \mathrm{~h}$, respectively. Subsequently, cells were pelleted by centrifugation $\left(500 \mathrm{x} \mathrm{g}\right.$ for $5 \mathrm{~min}$ at $\left.4^{\circ} \mathrm{C}\right)$ and washed with cold PBS. Cell pellets were resuspended in the radioimmunoprecipitation assay buffer (Beyotime Institute of Biotechnology) containing protease inhibitor (protease inhibitor cocktail; Roche Diagnostics, Basel, Switzerland), and lysed by bath sonication (4 times for $30 \mathrm{sec}$ on/off). Lysates were centrifuged $\left(15,000 \times \mathrm{g}\right.$ for $30 \mathrm{~min}$ at $\left.4^{\circ} \mathrm{C}\right)$ and the concentration of proteins were diluted to $3 \mu \mathrm{g} / \mu \mathrm{l}$ with $5 \mathrm{X}$ sample loading buffer (as determined by BCA assay). Samples were boiled at $100^{\circ} \mathrm{C}$ for $5 \mathrm{~min}$. Following this, the extracted proteins (30 $\mu \mathrm{g}$ per lane) were separated by SDS-PAGE on Bis-Tris 4-12\% gradient gels, transferred to polyvinylidene difluoride membranes and detected using specific antibodies. The membranes were blocked using 5\% skimmed milk at room temperature for $2 \mathrm{~h}$ and incubated with appropriate primary antibodies at $4{ }^{\circ} \mathrm{C}$ overnight. The following antibodies were used: Monoclonal anti-ERp57 (cat. no. sc80648), anti-TUBB3 (cat. no. sc-69966), anti-STAT3 (cat. no. sc8019) and anti-phospho(p)-STAT3 (Tyr705) antibodies (cat. no. sc81523) from Santa Cruz Biotechnology Inc. (Santa Cruz, CA, USA); monoclonal anti-phospho-glycoprotein (P-gp) antibodies (cat. no. ab170904) from Abcam (Cambridge, UK); polyclonal anti-p53 (cat. no. 10442-1-AP), anti-nucleolin (cat. no. 10556-1-AP) and monoclonal anti-GAPDH antibodies (cat. no.60004-1-lg) from ProteinTech Group Inc. (Wuhan, China); polyclonal anti-proliferating cell nuclear antigen (PCNA; cat. no. WL01804), anti-B-cell lymphoma B-cell lymphoma-extra large (Bcl-xl; cat. no. WL01558), anti-matrix metalloproteinase (MMP)1 (cat. no. WL01201), anti-MMP2 (cat. no. WL01579a), anti-MMP9 (cat. no. WL01580) and anti-vimentin antibodies (cat. no. WL00742) from Wanlei Biotechnology Inc. (Shenyang, China); and anti-B-cell lymphoma-2 (Bcl-2; cat. no. D260117) and anti-Bcl-2-associated X protein (Bax; cat. no. D120073) from Sangon Biotechnology Inc. (Shanghai, China). The primary antibodies were diluted to $1: 800$. Thereafter, the membranes were incubated with the secondary antibodies (anti-rabbit cat. no. ZB-2301 or anti-mouse cat. no. ZB-2305; ZSGB-Bio, Beijing, China) for $1 \mathrm{~h}$ at room temperature. The secondary antibodies were diluted to 1:10,000. Finally, the immune reactive proteins were detected using an enhanced chemiluminescence kit (cat. no. WLA003a; Wanlei Life Science, Shenyang, China) and the enhanced chemiluminescence detection system (Tanon-5200; Tanon Science and Technology Co., Ltd., Shanghai, China).

$R T-q P C R$. SKOV3 and SKOV3/tax cells were incubated at the density of $2 \times 10^{6}$ cells/well in $4 \mathrm{ml}$ of RPMI-1640 supplemented with $10 \%$ fetal bovine serum for $48 \mathrm{~h}$. Once cells were collected and washed with PBS, total RNA was extracted using TRIzol reagent (Invitrogen; Thermo Fisher Scientific, Inc.) and cDNA was obtained with RT using a PrimeScript RT Reagent kit (Takara Bio, Inc., Otsu, Japan). qPCR was performed using SYBR Premix Ex Taq II (Takara Bio, Inc.) according to the manufacturer's protocols. The following primers were used in the present study: ERp57, forward 5'-GAGCAATGATGGGCC TGTGA-3' and reverse 5'-TGACGATATTTGGGTCTTTGC TGA-3'; and GAPDH, forward 5'-TGCACCACCAACTGCTT AGC-3' and reverse 5'-GGCATGGACTGTGGTCATGAG-3'. The PCR process was performed using an ABI PRISM 7500 system (Applied Biosystems; Thermo Fisher Scientific, Inc.). PCR was performed as follows: $95^{\circ} \mathrm{C}$ for $30 \mathrm{sec}$; followed by 40 cycles of $95^{\circ} \mathrm{C}$ for $5 \mathrm{sec}$ and $60^{\circ} \mathrm{C}$ for $34 \mathrm{sec}$; and 1 cycle of $95^{\circ} \mathrm{C}$ for $15 \mathrm{sec}, 60^{\circ} \mathrm{C}$ for $1 \mathrm{~h}$ and $95^{\circ} \mathrm{C}$ for $15 \mathrm{sec}$. RT-qPCR data were normalized using GADPH as an internal standard and analyzed using the $2^{-\Delta \Delta \mathrm{Cq}}$ method (14).

Clonogenic assay. SKOV3 and SKOV3/tax cells were transfected with ERp57-siRNA, respectively, for $48 \mathrm{~h}$, then harvested and washed with PBS. Similarly, SKOV3 and SKOV3/tax cells were also transfected with NC-siRNA for comparison. A total of 500 cells/well were plated for $1-2$ weeks at $37^{\circ} \mathrm{C}$. Cells were fixed with $10 \%$ paraformaldehyde at room temperature for $30 \mathrm{~min}$. Colonies were stained with $0.25 \%$ of crystal violet at room temperature for $30 \mathrm{~min}$ and counted using Image J (version 1.46r) software (National Institutes of Health, Bethesda, MD, USA).

Cell migration analysis. The cell migration capability was examined using the Transwell assay (24-well insert; pore size, $8 \mu \mathrm{m}$; Corning Inc., NY, USA). Cells transfected with ERp57-siRNA or NC-siRNA for $48 \mathrm{~h}$ were harvested, suspended $\left(5 \times 10^{4}\right.$ cells/well) in $100 \mu 1$ serum-free RPMI-1640 medium, and loaded on the upper chamber. A total of $500 \mu \mathrm{l}$ complete RPMI-1640 medium (containing 10\% fetal serum albumin) was added in the lower chamber. Following $24 \mathrm{~h}$ of incubation, cells were fixed with $10 \%$ paraformaldehyde at room temperature for $30 \mathrm{~min}$ and free cells were removed carefully from the upper surface of the filter with a cotton swab. Migrated cells on the lower side of the filter were stained with $0.5 \%$ crystal violet for $1 \mathrm{~h}$ at room temperature and counted from five random fields under a optic microscope (magnification, x200) using ImageJ (version 1.46r) software.

Apoptosis assay. Cells were subjected to paclitaxel treatment and compared with those without this treatment. In the non-treatment group, SKOV3/tax cells were transfected with NC-siRNA, ERp57-siRNA and blank for $48 \mathrm{~h}$, respectively, and then harvested directly without paclitaxel treatment. In the paclitaxel-treated group, SKOV3/tax cells were treated with NC-siRNA, ERp57-siRNA and blank for $48 \mathrm{~h}$, respectively, followed by treatment with $10 \mathrm{nM}$ paclitaxel for $24 \mathrm{~h}$, and then harvested. For comparison, one extra sample was prepared: SKOV3/tax cells were treated with $1 \mathrm{mM}$ DNTB for $48 \mathrm{~h}$, followed by $10 \mathrm{nM}$ paclitaxel treatment for $24 \mathrm{~h}$, and then harvested. After the cells were harvested, all the samples were resuspended with $100 \mu \mathrm{l}$ binding buffer $(140 \mathrm{mmol} / \mathrm{l} \mathrm{NaCl}$, $5 \mathrm{mmol} / 1 \mathrm{CaCl}_{2}$ and $10 \mathrm{mmol} / 1 \mathrm{HEPES}$ buffer) and washed three times with PBS (pH 7.4). A total of $5 \mu$ Annexin V-fluorescein isothiocyanate and $10 \mu \mathrm{l}$ propidium iodide (Beijing Biosea Biotechnology, Co., Ltd., Beijing, China) were added and the cell suspension was incubated at room temperature in dark for $10 \mathrm{~min}$. Following centrifugation, the cell pellet was resuspended in $200 \mu \mathrm{l}$ binding buffer and analyzed using a FACSort flow cytometer (BD Biosciences, San Jose, CA, USA). The percentage of apoptotic and necrotic cells was determined using FCS express software (version 3.0; DeNovo Software, Los Angeles, CA, USA).

Bioinformatics analysis. The protein-protein interaction (PPI) network was established using the online tool STRING 
A

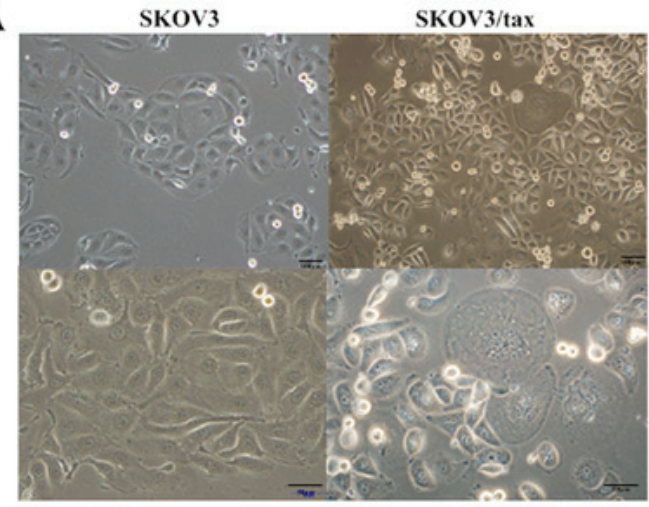

C
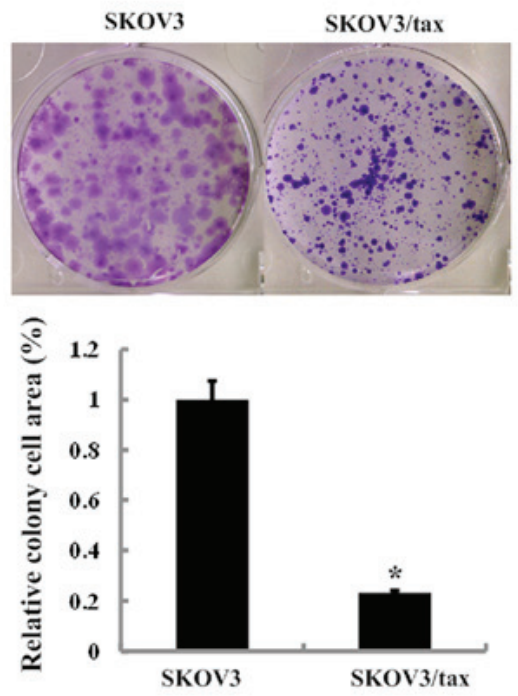

E

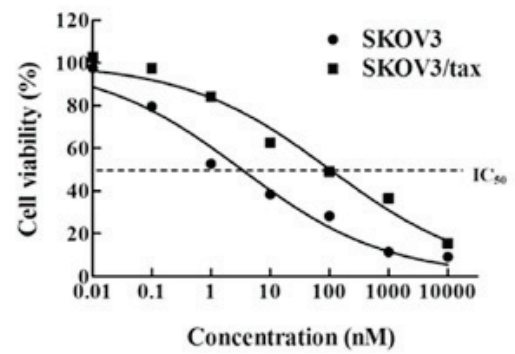

B

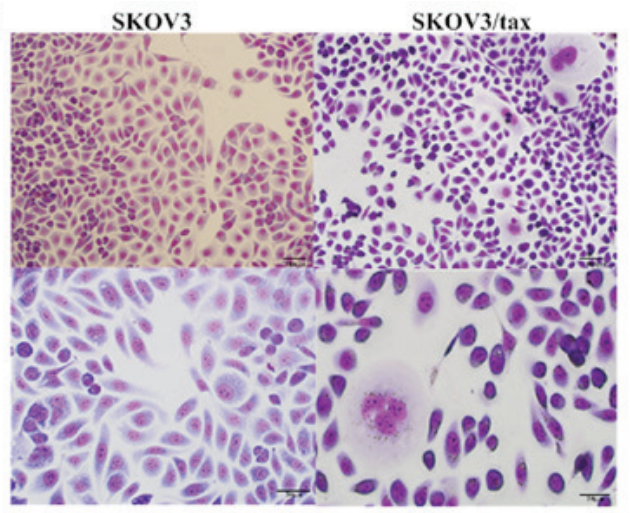

D

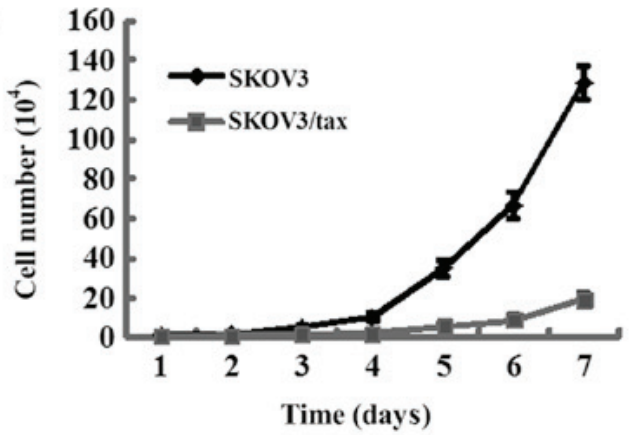

$\begin{array}{lllll}\text { F } & \text { SKOV3 } & \text { SKOV3/tax } & \text { SKOV3 } & \text { SKOV } 3 / \operatorname{tax}\end{array}$

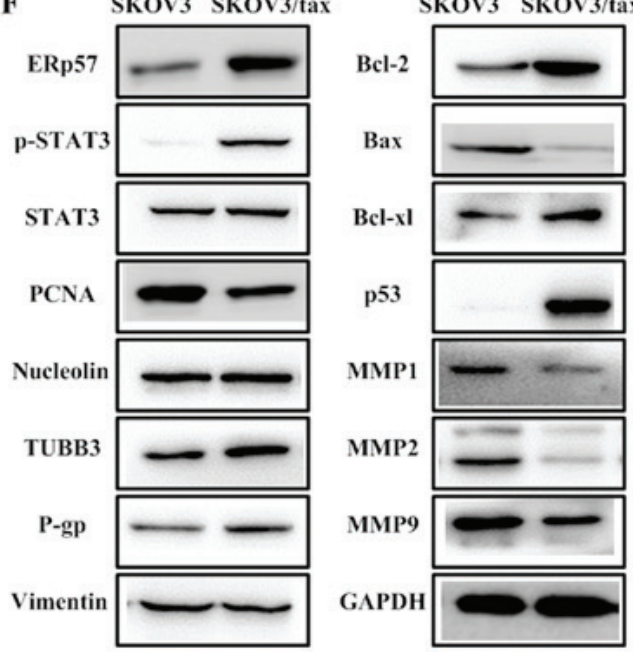

Figure 1. Characterization of paclitaxel-sensitive ovarian cells SKOV3 and paclitaxel-resistant ovarian cells SKOV3/tax. (A) Cell morphology observed under optic microscope. Original magnifications, x100 (upper images) and x200 (lower images). (B) Cell morphology observed under an optic microscope using Giemsa staining. Original magnifications, x100; (upper images), magnification, x200. (lower images). (C) Cellular proliferation was examined using colony formation assays. "P<0.05 vs. SKOV3. (D) Cellular proliferation curves. (E) Cell viability of SKOV3 cells and SKOV3/tax cells at different paclitaxel concentrations were determined by MTT assay. (F) Western blot analyses of selected proteins of SKOV3 and SKOV3/tax cells. GAPDH was used as the internal standard.

(string-db.org) (15). The gene/protein-gene/protein interaction network was generated with GeneMANIA (genemania.org) (16). Biological process and gene co-occurrence analysis was performed using COREMINE (coremine/medical) (17). Pathway enrichment analysis was performed using DAVID (david.abcc.ncifcrf.gov) (18).

Statistical methods. Data analysis was performed using SPSS software 17.0 (SPSS, Inc., Chicago, IL, USA). All experimental data were expressed as the mean \pm standard deviation and statistically analyzed. The statistical significance of the results was assessed using one-way analysis of variance followed by Tukey's post hoc multiple comparison tests. $\mathrm{P}<0.05$ was considered to indicate a statistically significant difference. All the measurements were repeated at least three times.

\section{Results}

Characterization of paclitaxel-resistant ovarian cancer cell lines. SKOV3/tax cells were characterized. The difference in cell morphology between SKOV3 and SKOV3/tax cells was clarified under an optic microscope and with Giemsa staining (Fig. 1A and B). Notably, more vesicles and vacuoles were observed in SKOV3/tax cells compared with SKOV3 cells.

Cell proliferation was examined using the clonogenic assay. Equal numbers of SKOV3 and SKOV3/tax cells were 
A

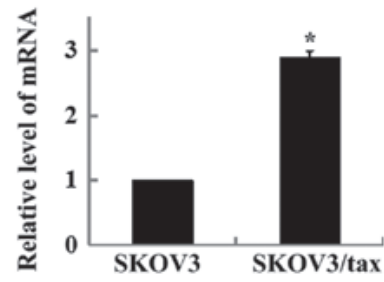

C

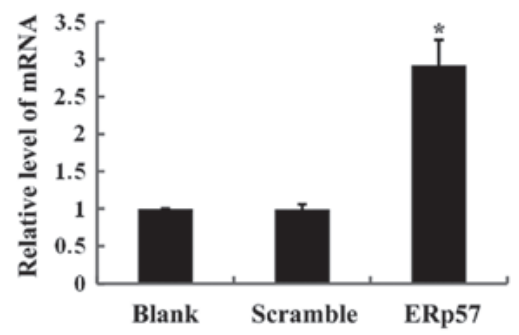

$\mathbf{E}$

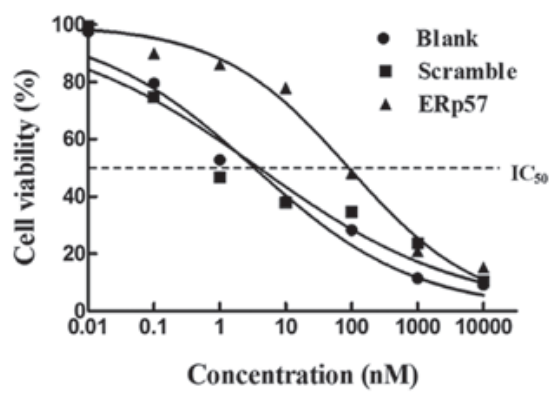

B

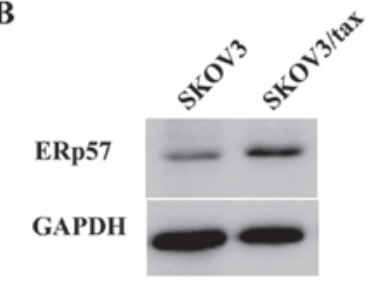

D

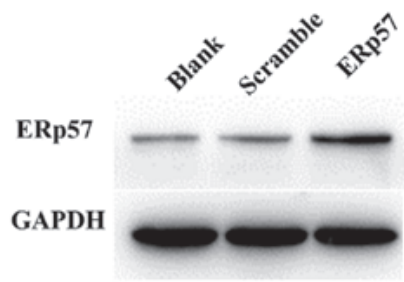

Figure 2. ERp57 expression in SKOV3, SKOV3/tax cells and SKOV3 cells treated with ERp57 overexpression lentiviral particle infection. (A) ERp57 mRNA expression levels in SKOV3 and SKOV3/tax cells were detected by RT-qPCR. "P $<0.05$ vs. SKOV3. (B) Protein expression levels of SKOV3 and SKOV3/tax cells were analyzed using western blot analysis. GAPDH was used as the internal standard. (C) The ERp57 mRNA levels of SKOV3 cells treated with blank, scramble and ERp57 lentiviral particles were detected by RT-qPCR. "P<0.05 vs. scramble. (D) Western blot analysis of ERp57 expression levels in SKOV3 cells treated with blank, scramble and ERp57 lentiviral particles, respectively. GAPDH was used as the internal standard. (E) Cell viability was determined by MTT assay once SKOV3 cells were treated with blank, scramble and ERp57 lentiviral particles, and different paclitaxel concentrations. RT-qPCR, reverse transcription-quantitative polymerase chain reaction.

cultured for 2 weeks and colony numbers were subsequently counted. SKOV3/tax cells grew significantly slower compared with SKOV3 cells $(\mathrm{P}<0.05$; Fig. 1C). Cell population doubling times were estimated to be $\sim 22 \mathrm{~h}$ for SKOV3 cells and $36 \mathrm{~h}$ for SKOV3/tax cells, respectively (by a factor of 1.6; Fig. 1D). The $\mathrm{IC}_{50}$ values of SKOV3 and SKOV3/tax cells to paclitaxel were determined based on the growth curves in Fig. 1E to be $3.24 \pm 0.03$ and $101.06 \pm 0.99 \mathrm{nM}$, respectively. The drug-resistance index of SKOV3/tax to SKOV3 was calculated to be $>30$-fold. These data confirmed the paclitaxel-resistant characteristics of SKOV3/tax cells.

Furthermore, several proteins associated with apoptosis (Bcl-2, Bax, Bcl-xl and p53), migration (MMP1, MMP2, MMP9 and vimentin), cell proliferation (PCNA and nucleolin) and drug-resistance (P-gp and TUBB3) were compared in SKOV3 and SKOV3/tax cells using western blot analysis to assess paclitaxel-resistant behavior (Fig. 1F). The expression levels of MDR phenotype biomarkers P-gp and TUBB3 were increased in SKOV3/tax cells compared with SKOV3 cells. Protein PCNA and nucleolin expression levels were considered biomarkers for cell proliferation. Notably, PCNA expression levels were reduced in SKOV3/tax cells compared with SKOV3 cells. By contrast, nucleolin expression levels were similar in SKOV3/tax and SKOV3 cells. Weak p-STAT3 expression was indicated in SKOV3 cells; however, p-STAT3 protein expression levels were increased in SKOV3/tax cells.
In $\mathrm{SKOV} 3 /$ tax cells, apoptosis-inhibiting proteins $\mathrm{Bcl}-2$ and Bcl-xl were highly expressed, whereas the apoptosis promoting protein Bax was expressed in lower levels. The SKOV3 cell is a p53-mutant cell line that does not express p53 (19); however, p53 was highly expressed in SKOV3/tax cells. MMP1, MMP2 and MMP9 proteins, which are associated with metastasis (20), were expressed in lower levels in SKOV3/tax cells compared with SKOV3 cells, suggesting a lower invading ability of SKOV3/tax cells. Furthermore, an epithelial-mesenchymal transition (EMT) protein marker, vimentin, was expressed to almost at the same level in SKOV3 and SKOV3/tax cells.

ERp57 overexpression of paclitaxel-resistant SKOV3/tax cells. ERp57 mRNA and protein expression levels were compared in SKOV3 and SKOV3/tax cells using RT-qPCR and western blot analysis. As indicated in Fig. 2A, mRNA expression levels of ERp57 in SKOV3/tax cells were $>2$-fold higher than that of SKOV3 cells $(\mathrm{P}<0.05)$. In addition, western blot analysis results also revealed that the expression level of ERp57 protein in SKOV3/tax cells was upregulated (Fig. 2B). These data were consistent with a previous report (21), which indicated that ERp57 is strongly associated with the paclitaxel-resistant ovarian cancer cells SKOV3/tax.

To examine the effect of ERp57 overexpression on the paclitaxel sensitivity of SKOV3 cells, ERp57 was overexpressed 

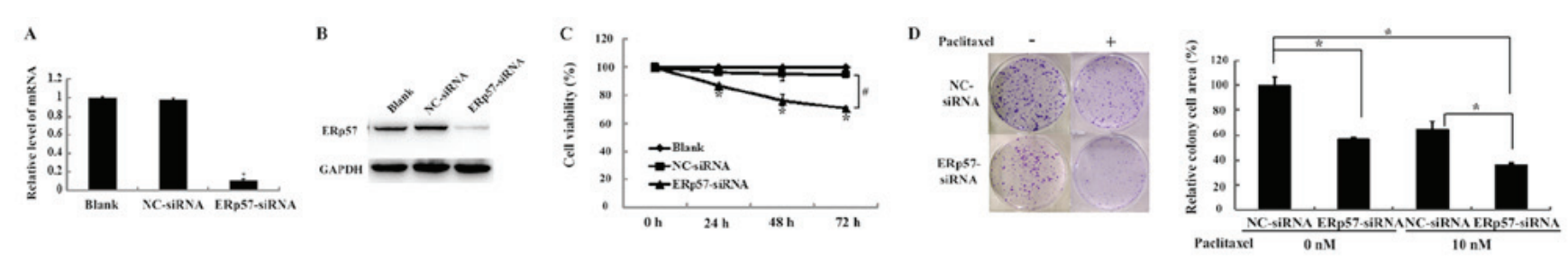

E
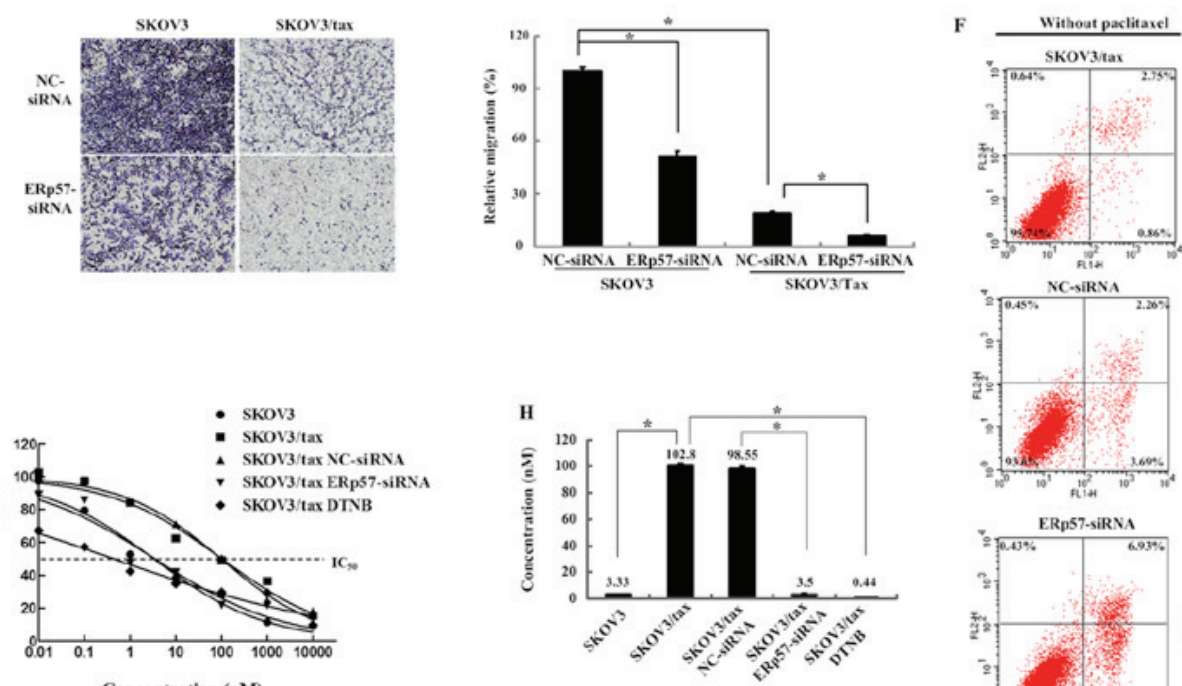
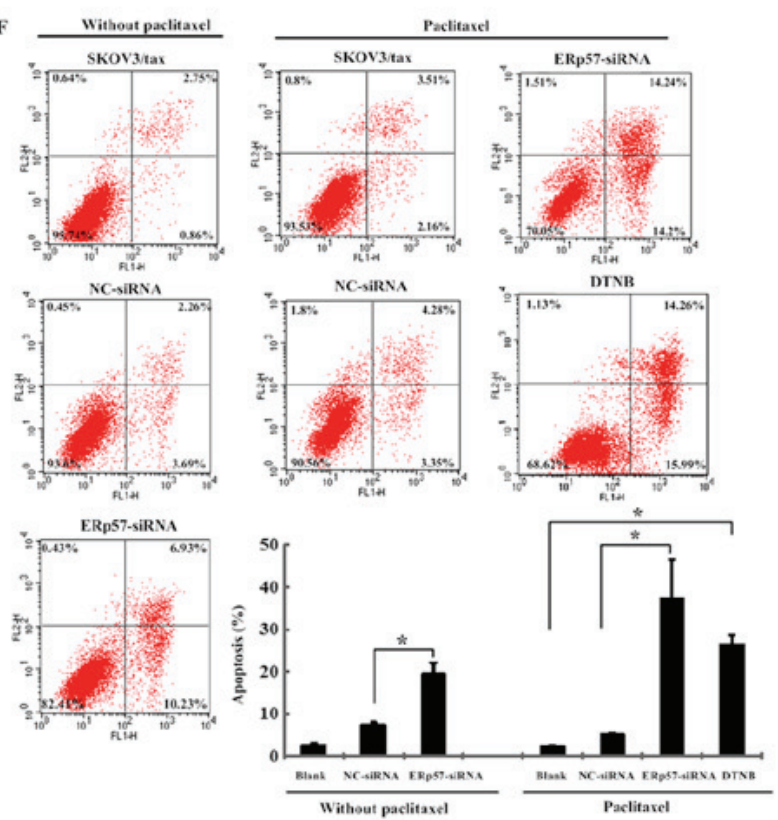

Figure 3. Cellular and molecular responses of SKOV3/tax cells following different treatments. (A) The ERp57 mRNA expression levels of SKOV3/tax cells treated with blank, NC-siRNA and ERp57-siRNA were detected by reverse transcription-quantitative polymerase chain reaction. * $<<0.05$ vs. NC-siRNA. (B) ERp57 protein expression levels of SKOV3/tax cells treated with blank, NC-siRNA and ERp57-siRNA, respectively. GAPDH was used as the internal standard. (C) Cell viability analysis of SKOV3/tax (treated with blank, NC-siRNA and ERp57-siRNA, respectively) for different time periods (0, 24, 48 and $72 \mathrm{~h}$ ) using the MTT assay. ${ }^{*} \mathrm{P}<0.05$ vs. NC-siRNA at $0 \mathrm{~h} ;{ }^{*} \mathrm{P}<0.05$ as indicated. (D) Cellular proliferation was examined using colony formation assays. ${ }^{*} \mathrm{P}<0.05$ as indicated. (E) Cell migration was assessed using Transwell assays (original magnifications, $\mathrm{x} 40$ ). ${ }^{*} \mathrm{P}<0.05$ as indicated. (F) Cell apoptosis was detected by flow cytometric analyses. " $\mathrm{P}<0.05$ as indicated. (G) Cell viability analysis was assessed by the MTT assay. (H) IC ${ }_{50}$ of SKOV3, SKOV3/tax, SKOV3/tax treated with NC-siRNA, SKOV3/tax treated with ERp57 and SKOV3/tax treated with ERp57 inhibitor DTNB, respectively. ${ }^{\text {P }<0.05}$ as indicated.

in SKOV3 cells (Fig. 2C and D). As indicated in Fig. 2E, the $\mathrm{IC}_{50}$ values of untransfected $\mathrm{SKOV} 3$ cells and scramble control were $3.33 \pm 1.18$ and $3.897 \pm 1.39 \mathrm{nM}$. However, the $\mathrm{IC}_{50}$ value of ERp57-overexpressed SKOV3 cells was increased to $90.59 \pm 1.13 \mathrm{nM}$. These data indicated that ERp57 overexpression could increase drug resistance of SKOV3 cells.

Paclitaxel sensitivity of SKOV3/tax affected by ERp57-siRNA silencing. The effect of ERp57-siRNA silencing on the sensitivity of SKOV3/tax cells to paclitaxel was examined. As indicated in Fig. 3A, ERp57-siRNA silencing significantly inhibited the expression levels of ERp57 mRNA $(\mathrm{P}<0.05)$. Similarly, western blot analysis results demonstrated that ERp57 protein expression levels were also inhibited (Fig. 3B). As indicated in Fig. 3C, ERp57-siRNA silencing significantly downregulated the viability of SKOV3/tax cells at 24, 48 and $72 \mathrm{~h}(\mathrm{P}<0.05)$, and the cell viability percentages were determined to be 87,76 and $71 \%$ at the respective time-points. By contrast, NC-siRNA did not significantly alter the cell viability of SKOV3/tax cells.

Following ERp57-siRNA silencing, the numbers and the size of the colonies of SKOV3/tax cells were significantly reduced compared with the control $(\mathrm{P}<0.05$; Fig. 3D, top left vs. lower left). Furthermore, after ERp57-siRNA silencing, a total of $10 \mathrm{nM}$ paclitaxel decreased the colony formation and number of SKOV3/tax colonies by $\sim 60 \%$ when compared with the control with no paclitaxel treatment $(\mathrm{P}<0.05$; Fig. 3D, top left vs. lower right). The Transwell assay was used to examine the migration ability of SKOV3 and SKOV3/tax cells. As indicated in Fig. 3E, the migration ability of SKOV3 cells was significantly increased compared with SKOV3/tax cells $(\mathrm{P}<0.05)$. ERp57-siRNA silencing could significantly reduce the cell migration of SKOV3 and SKOV3/tax cells $(\mathrm{P}<0.05)$.

The effects of ERp57-siRNA silencing on SKOV3/tax cell apoptosis were examined using Annexin V and PI double staining. The apoptosis rate of the ERp57-silenced cells was $17.16 \%$, which was significantly higher than the apoptosis rate in the control (3.61\%) and NC-siRNA cells $(5.95 \%$; $\mathrm{P}<0.05$; Fig. 3F). Furthermore, in SKOV3/tax cells treated with paclitaxel, the apoptosis rates of the control and NC-siRNA cells were 5.67 and $7.63 \%$, whereas the apoptosis rate of ERp57-siRNA cells was significantly increased to $\sim 38 \%$ (mean of the three measurements; $\mathrm{P}<0.05$ ). For comparison, the effect of the ERp57 inhibitor DNTB was examined, and the results indicated that the apoptosis rate of SKOV3/tax cells was $29.7 \%$.

Cell viability of SKOV3/tax cells under different conditions was assessed using the MTT assay. Fig. 3G and $\mathrm{H}$ revealed the 

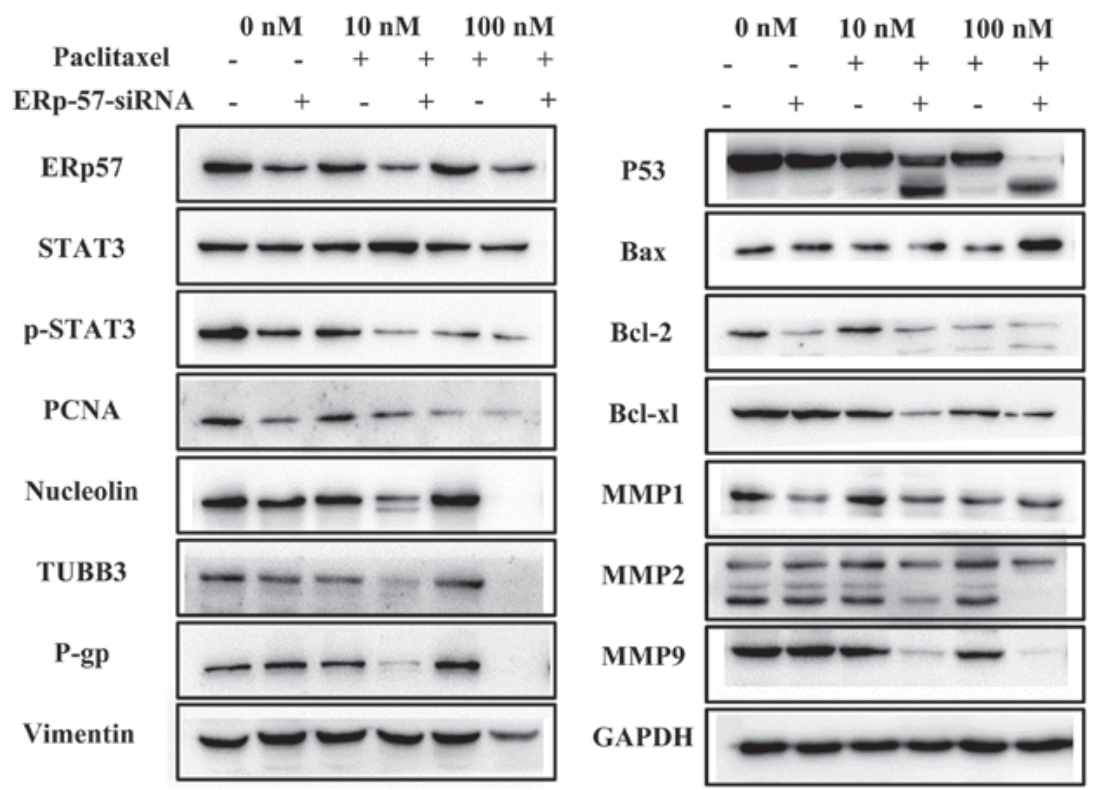

Figure 4. Western blot analyses of selected proteins of SKOV3/tax cells pre-treated with ERp57-siRNA silencing, followed by different dosages of paclitaxel treatment. GAPDH was used as the internal standard.

growth curves and the calculated $\mathrm{IC}_{50}$ values of the different samples. The $\mathrm{IC}_{50}$ values of SKOV3 and SKOV3/tax cells were $\sim 3.33 \pm 1.18$ and $102.8 \pm 1.17 \mathrm{nM}$, respectively. The $\mathrm{IC}_{50}$ values of SKOV3/tax cells were reduced to $3.5 \pm 1.15$ and $0.44 \pm 1.3 \mathrm{nM}$ following treatment with ERp57-siRNA or DTNB, respectively (Fig. 3H). These data indicated that ERp57-siRNA silencing could restore the sensitivity of SKOV3/tax cells to paclitaxel.

The expression levels of the selected protein biomarkers were assessed in cells treated with ERp57-siRNA and paclitaxel. As indicated in Fig. 4, when SKOV3/tax cells were treated with ERp57-siRNA alone, protein P-gp expression was not significantly impacted (columns 1 and 2). However, once paclitaxel was applied, P-gp expression levels were decreased in a concentration-dependent manner (columns 4 and 6), which suggested that pre-treatment of ERp57-siRNA effectively inhibited P-gp protein expression and increased paclitaxel efficacy. The MDR biomarker TUBB3 also exhibited a similar trend. The expression level of PCNA was reduced and that of nucleolin was marginally altered in response to paclitaxel (columns 1, 3 and 5). When ERp57-siRNA was applied, PCNA and nucleolin expression levels were further reduced in the presence of paclitaxel in a concentration dependent-manner (columns 2, 4 and 6). Furthermore, western blot analysis revealed that co-treatment of ERp57-siRNA and paclitaxel reduced the p-STAT3 expression levels in a dose-dependent manner (columns 2, 4 and 6). Additionally, Bcl-2 and Bcl-xl expression levels were downregulated when ERp57-siRNA and $100 \mathrm{nM}$ paclitaxel were used (columns 4 and 6), whereas the apoptosis promoting protein Bax was highly expressed.

Paclitaxel treatmentalone didnotimpactp53expression, even at $100 \mathrm{nM}$, due to the drug-resistant phenotype of SKOV3/tax cells (columns 1, 3 and 5). In addition, p53 expression was not affected by ERp57-siRNA alone (column 2). However, when ERp57-siRNA was combined with $10 \mathrm{nM}$ paclitaxel, the p53 band was markedly reduced, and its isoform p53/p47 became merged (column 4). When ERp57-siRNA was combined with $100 \mathrm{nM}$ paclitaxel, the p53 band was further reduced and the p53/p47 band was highly expressed (column 6). Notably, MMP1 and MMP2 protein expression levels were reduced when paclitaxel and/or ERp57-siRNA were applied. However, MMP9 protein expression was unchanged with ERp57-siRNA treatment alone (columns 1 and 2) and a minor reduction in expression was observed with treatment of paclitaxel alone (10 or $100 \mathrm{nM}$ ) (columns 1, 3 and 5). When ERp57-siRNA was combined with paclitaxel, MMP9 expression was markedly reduced with $10 \mathrm{nM}$ paclitaxel and completely eliminated with $100 \mathrm{nM}$ paclitaxel (columns 4 and 6). No notable changes were indicated with regards to the expression of the EMT marker vimentin with paclitaxel and/or ERp57-siRNA treatment; however, a reduction was observed with $100 \mathrm{nM}$ paclitaxel and ERp57-siRNA treatment (column 6).

Bioinformatics analyses of ERp57 and drug resistance in ovarian cancer. In order to understand the underlying mechanisms of ERp57 in drug-resistant ovarian cancer, STRING was used to construct a PPI network between ERp57 (PDIA3) and STAT3, P-gp (ABCB1), TUBB3, p53 (TP53), Bcl-2, Bax, Bcl-xl (BCL2L1), vimentin, PCNA, nucleolin, MMP1, MMP2 and MMP9. As indicated in Fig. 5A, ERp57 (referred as PDIA3 in STRING) has direct interactions with STAT3 and vimentin. ERp57 can have the indirect interactions with p53, Bcl-2, Bax, Bcl-x1, PCNA, MMP1, MMP2 and MMP9 proteins via STAT3, and indirect interactions with p53, Bcl-2, PCNA, MMP1, MMP2 and MMP9 via vimentin. Furthermore, ABCB1 can be regulated indirectly by ERp57 via p53 and Bax. GeneMANIA was used to construct a gene/protein-gene/protein interaction network between ERp57 (PDIA3) and various other components, including calnexin (CANX), calreticulin (CALR), transporter 1 (TAP1), transporter 2 (TAP2), TAP binding protein (TAPBP), protein disulfide isomerase family A member 4 (PDIA4), protein 
A

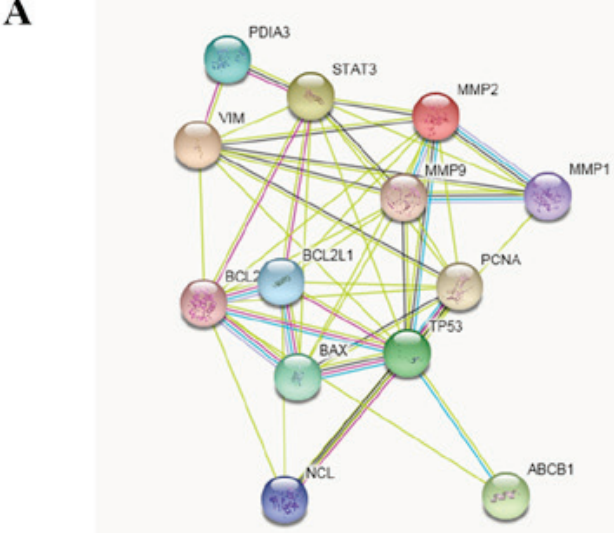

B
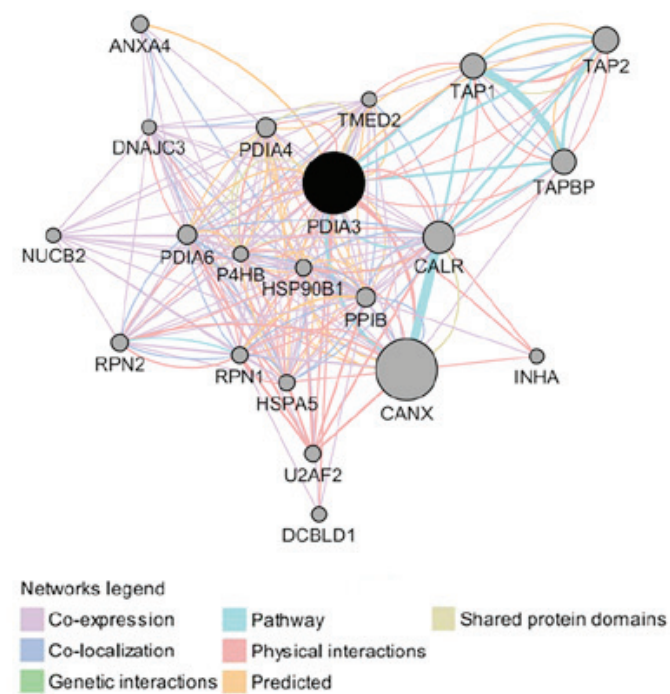

D

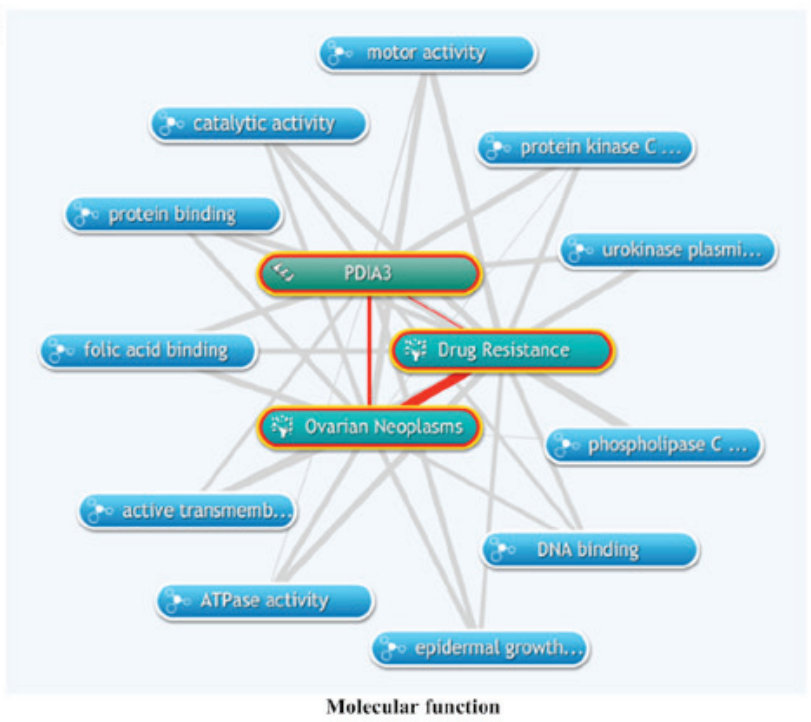

Figure 5. Comprehensive bioinformatics analyses of ERp57. (A) Protein-protein interaction network of the selected proteins using the online tool STRING. (B) Protein/gene-protein/gene interaction network of ERp57 using the online tool GeneMANIA. (C) Annotation of the biological processes of ERp57 with ovarian cancer and drug resistance using the online database/tool Coremine Medical. The top 27 biological processes were associated with the three terms were annotated $(\mathrm{P}<0.01)$. (D) Annotation of the molecular function of ERp57 with ovarian cancer and drug resistance using the Coremine Medical online database/tool. The top 11 molecular functions were associate with the three terms were annotated $(\mathrm{P}<0.05)$.

disulfide isomerase family A member 6 (PDIA6) and heat shock protein $90 \mathrm{kDa}$ beta family member 1 (HSP90B1). As indicated in Fig. 5B, ERp57 had strong interactions with 20 proteins/genes. Co-expressed ERp57 had strong physical interactions and shared a pathway with CANX and CALR. Furthermore, CANX was associated with ATP transporter-associated proteins/genes (ABCB1, ABCC1 and $\mathrm{ABCC} 3)$ and apoptosis-associated proteins/genes [Bcl-2, poly (ADP-ribose) polymerase 1 (PARP1), caspase-3 (CASP3), p53]. ABCB1, ABCC1, ABCC3, Bcl-2, PARP1 and CASP3 expression changes have been associated with drug resistance (22-26). The findings suggested that inference of ERp57 must be associated with drug resistance in ovarian cancer.

The associated biological processes of ERp57 with ovarian cancer and drug resistance were assessed using COREMINE. The results indicated that a total of 25 biological processes were associated with ERp57, ovarian cancer and drug resistance $(\mathrm{P}<0.01)$, including cell death (autophagy, cell killing, cell death and the apoptotic process), cell growth (cell proliferation, cell growth, growth, cell division and angiogenesis), the cell cycle (cell cycle, cell cycle arrest and $\mathrm{S}$ phase), gene expression regulation (RNA interference, gene silencing, gene expression, DNA methylation, methylation, phosphorylation, mismatch repair, DNA repair and signal transduction), platelets (platelet activation and platelet aggregation), cell migration, metabolism and protein folding-associated processes (Fig. 5C). These results suggested that either ERp57 may be a regulator of these processes or these processes contribute the development of drug resistance phenotype of ovarian cancer.

Fig. 5D indicated that a total of 11 molecular functions, including folic acid binding, protein binding, catalytic activity, 
Table I. Pathway enrichment analysis of the 31 genes which co-occurred with ERp57, drug resistance and ovarian cancer, in accordance with DAVID.

\begin{tabular}{llll}
\hline $\begin{array}{l}\text { Kyoto Encyclopedia of Genes } \\
\text { and Genomes pathway }\end{array}$ & $\begin{array}{l}\text { P-value } \\
(<0.01)\end{array}$ & $\begin{array}{c}\text { Benjamini } \\
(<0.05)\end{array}$ & $\begin{array}{c}\text { Genes co-occurring with ERp57, } \\
\text { drug resistance and ovarian cancer }\end{array}$ \\
\hline Pathway in cancer & $6.80 \times 10^{-9}$ & $2.00 \times 10^{-7}$ & $\begin{array}{l}\text { BCL2, BCL2L1, CASP3, CASP9, EGFR, GSTP1, } \\
\text { HSP90AA1, PTEN, STAT3, P53, ERBB2 }\end{array}$ \\
Apoptosis & $3.10 \times 10^{-4}$ & $2.60 \times 10^{-3}$ & BCL2, BCL2L1, CASP3, CASP9, TP53 \\
p53 signaling pathway & $2.20 \times 10^{-3}$ & $1.40 \times 10^{-2}$ & CASP3, CASP9, PTEN, TP53 \\
Focal adhesion & $7.00 \times 10^{-3}$ & $3.70 \times 10^{-2}$ & BCL2, COL11A2, EGFR, PTEN, ERBB2
\end{tabular}

BCL2, B-cell lymphoma-2; BCL2L1, BCL2-like 1; CASP3, caspase-3; CASP9, caspase-9; EGFR, epidermal growth factor receptor; GSTP1, glutathione S-transferase pi gene; HSP90AA1, heat shock protein 90 alpha family class A member 1; PTEN, phosphate and tension homolog deleted on chromsome 10; STAT3, signal transducer and activator of transcription 3; P53, Tumor protein p53; ERBB2, receptor tyrosine-protein kinaseerbB-2; COLL11A2, collagen alpha-2(XI) chain.

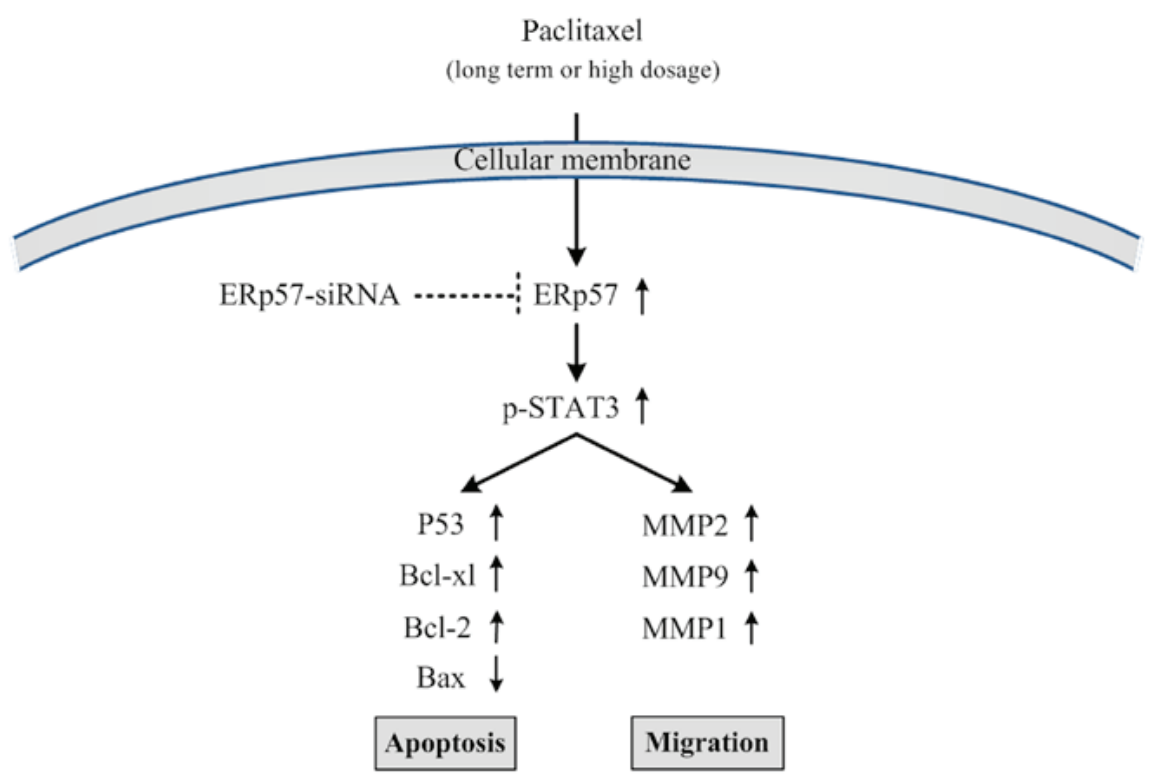

Figure 6. A model of the biological role of ERp57 in paclitaxel-resistant SKOV3/tax human ovarian cancer cells and the paclitaxel sensitivity reversal of SKOV3/tax by siRNA silencing.

motor activity, protein kinase $\mathrm{C}$ activity, urokinase plasminogen activator receptor activity, phospholipase $\mathrm{C}$ activity, DNA binding, epidermal growth factor binding, ATPase activity and active transmembrane transporter activity were predicted to be associated with ERp57, ovarian cancer and drug resistance $(\mathrm{P}<0.05)$. Furthermore, pathway enrichment analysis was performed using DAVID, which revealed a total of 31 genes (finding by Coremine Medical) co-occurred with ERp57 and drug resistance in ovarian cancer (Table I). Many familiar genes were indicated, including BCL2, PARP1, STAT3, CASP3, CASP9, vimentin, phosphatase and tensin homolog, Erb-B2 receptor tyrosine kinase 2, heat shock protein $90 \beta 1$ and epidermal growth factor receptor. As indicated in Table I, ERp57 may be associated with drug resistance in ovarian cancer through its regulation on the four pathways: The cell death-associated pathways (apoptosis and p53 signaling pathway), the focal adhesion signaling pathway and the cancer related pathway.

\section{Discussion}

ERp57, also referred to as PDIA3, ER60, ERp60, GRp58, Q2 and 1,25D3-MARRS receptor, is a widely expressed protein with multiple biological functions (27). Being a member of the disulfide isomerase family, ERp57 has been studied extensively as an endoplasmic reticulum (ER) chaperone protein participating in the proper folding and reshuffling of disulfide bridges of newly synthesized proteins in ER, as well as in the assembly of major histocompatibility complex class-I molecules (28-31).

ERp57 is considered a stress-response protein, and its overexpression has been confirmed in various types of cancer, including breast, uterus, lung, stomach, cervical, head and neck cancer and laryngeal cancer $(32,33)$. Anti-cancer agents, particularly stress-inducing agents, can induce ERp57 upregulation, therefore providing a protective role against apoptosis in cancer cells under increased ER stress $(34,35)$. 
Thus, the ERp57 overexpression in chemoresistant cancer cells at mRNA and protein levels was not unanticipated $(11,12)$. Choe et al (36) demonstrated that ERp57 was upregulated in radioresistant laryngeal cancer cells. Unfortunately, little information was available regarding the biological effects of ERp57 on the chemoresistance phenotype. Therefore, the present study was designed to investigate the ERp57 roles in paclitaxel-resistant SKOV3/tax cells and the possibility of resensitizing SKOV3/tax cells to paclitaxel by ERp57 downregulation.

The present results indicated that the expression $\mathrm{Bcl}-2$ and Bcl-xl were overexpressed and Bax expression was significantly reduced in SKOV3/tax cells, suggesting the expression of apoptosis-associated proteins supported the drug resistance cellular phenotype. The apoptosis indicator, tumor repressor protein $\mathrm{p} 53$, was also increased in SKOV3/tax cells. Furthermore, the active form of STAT3, p-STAT3, was highly expressed in SKOV3/tax cells. These results implied that the paclitaxel-resistance of SKOV3/tax may be due to an apoptosis-associated mechanism and the activation of STAT3. Furthermore, the results suggested that paclitaxel-resistance was partly associated with an effluxing mechanism involving P-gp and the de-polymerization of TUBB3.

The present results suggested that ERp57-siRNA silencing improved the sensitivity of SKOV3/tax cells to paclitaxel. As confirmation, the expression levels of selected protein markers associated with the cellular behavior of SKOV3/tax cells were assessed. Following ERp57-siRNA silencing, P-gp and TUBB3 were expression levels were reduced in the presence of $10 \mathrm{nM}$ paclitaxel and completely inhibited in the presence of $100 \mathrm{nM}$ paclitaxel, suggesting that ERp57-siRNA silencing could restore the sensitivity of SKOV3/tax to paclitaxel.

With ERp57-siRNA silencing, $10 \mathrm{nM}$ paclitaxel reduced p53 expression by $\sim 50 \%$ and the expression of its isoform p53/p47 was increased. At $100 \mathrm{nM}$ paclitaxel, p53 expression was completely eliminated and the isoform p53/p47 became further increased. These results were consistent with a previous report (37). Transcriptionally active p53 tetramers bind to promoter regions and regulate gene products, which prevents cancer development (37). ER stress promotes protein kinase R-like ER kinase (PERK)-dependent induction of p53/p47 isoform (37). Furthermore, P53/p47 induces $G_{2}$ arrest but has no effect on $\mathrm{G}_{1}$ progression. It was reported that cells appear to favor $G_{2}$ arrest in response to ER-stress like paclitaxel treatment (37). A previous study indicated that the p53/p47 isoform was increased and H1299 and MLS1765 cells were arrested in $\mathrm{G}_{2}$ phase with the increase of thapsigargin dosage (38). Additionally, apoptosis-inhibiting Bcl-2 and Bcl-xl proteins were markedly reduced with ERp57-siRNA silencing in the present study. By contrast, the apoptosis-promoting protein Bax was upregulated. These results were consistent with the results that co-treatment of ERp57-siRNA and paclitaxel could increase the apoptosis rate of SKOV3/tax cells.

Tumorigenic STAT3 activation has been frequently linked to malignant cancer behavior, including growth, migration, invasion and metastasis (39). Previous studies have revealed an association between ERp57 and STAT3 $(40,41)$. In M14 melanoma cells, chromatin immunoprecipitation revealed that ERp57 binds to DNA in the proximity of STAT3 in a subset of STAT3-regulated genes. Upon depletion of ERp57, the quantity of p-STAT3 was reduced (41). It has been also reported that ERp57 and STAT3 are associated to $\alpha 2$-marroglobulin gene enhancer, when stimulated by interleukin- 6 , these two proteins are bound to the sis-inducible element sequence in HepG2 cells (42). Accumulated evidence has indicated that STAT3 activation was also associated with tumor chemoresistance. Gu et al (43) identified a correlation between enhanced STAT3 expression and cisplatin-resistance in patients with cancer, and blocking the Janus-kinase STAT3 signaling pathway could restore cisplatin sensitivity (43). Notably, it has been demonstrated that activating transcription factor 4 promotes the MDR phenotype in esophageal squamous-cell carcinoma (ESCC) cells by binding directly to the STAT3 promoter. However, inhibition of STAT3 could reintroduce therapeutic sensitivity (44). Ryu et al (45) reported that treatment with CDDO-Me significantly decreased the level of nuclear translocation and phosphorylation of STAT3. A previous study revealed that the inhibition of the STAT3 signaling pathway correlated with the suppression of the anti-apoptotic genes Bcl-xl, survivin and MCL-1 (45). The correlation between the STAT3 activation and the chemoresistance of cancer cells has been documented previously (46-48). In the present study, the high expression of the activated STAT3 and the chemoresistance of SKOV3/tax cells was confirmed, and the downregulation of p-STAT3 by ERp57-siRNA silencing was associated with the chemoresistance reversal of SKOV3/tax cells.

EMT is associated with drug resistance. In some cases MMPs are overexpressed (high invading) in drug-resistant cancer cells $(49,50)$, and in other cases MMPs are underexpressed (low invading) in drug-resistant cancer cells $(51,52)$. These findings suggest that the association of MMPs and drug resistance varies among different samples. Notably, the expression levels of EMT-associated proteins MMP1, MMP2, MMP9 and vimentin were lower in SKOV3/tax cells than that in SKOV3 cells, suggesting that SKOV3/tax cells exhibited less metastasis than SKOV3 cells. In the present study, ERp57 was highly expressed in less metastatic cells (SKOV3/tax), which was not in agreement with Naiara's observation that overexpression ERp57 was related to bone metastasis in breast cancer cell (53).

Although the role of ERp57 as a cell protective agent against apoptosis has been accepted, some controversial evidence has also emerged. Xu et al (54) suggested that ERp57-siRNA could significantly reduce hyperoxia- or tunicamycin-induced apoptosis in human endothelial cells by the inhibition of caspase-3 activation and stimulation of binding immunoglobulin protein/glucose-regulated protein 78 induction (54). It was also reported that ERp57 possesses $\mathrm{Bcl}-2$ homologous antagonist/killer-dependent proapoptotic function through inducing mitochondrial outer membrane permeabilization (55). These discrepancies are likely due to the differences in cellular context and tumor types as well as upstream regulators, parallel transcription co-regulators and downstream target genes of ERp57. Hence, these findings signify the pivotal role of ERp57 in the coordination of complex regulatory systems.

To further illustrate the potential association of ERp57 with drug resistance in ovarian cancer, comprehensive bioinformatics analyses were performed in the present study. 
A network of ERp57 and other proteins was constructed. ERp57 was predicted to directly regulate STAT3 and vimentin, and other proteins [P-gp, p53, Bcl-2, Bax, Bcl-xl (BCL2L1), nucleolin, PCNA, MMP1, MMP2 and MMP9] were linked with ERp57 indirectly. These predictions were partially consistent with the present experimental results that ERp57-siRNA silencing could directly decrease the expression of p-STAT3; however, the results indicated that ERp57 siRNA silencing could not affect the expression of vimentin directly in the present study. Protein/gene interaction analysis revealed a total 20 proteins/genes interactions with ERp57, 7 of which (CANX, TAP1, TAP2, PDIA4, PDIA6, HSP90B1 and ANXA4) were associated with drug resistance. The biological process annotation indicated that 25 biological processes, 11 molecular functions, 3 pathways and 36 genes co-occurred with ERp57, ovarian cancer and drug resistance.

In conclusion, the present study produced a model to interpret the biological role of ERp57 in paclitaxel-resistant SKOV3/tax cells and the paclitaxel sensitivity reversal of SKOV3/tax by siRNA silencing (Fig. 6). The findings suggested that long-term or high-dosage paclitaxel treatment of SKOV3 ovarian cancer cells leads to high ERp57 expression. As a result, the STAT3 signaling pathway was activated, which promotes cell survival by evading the apoptosis process. However, inhibition of ERp57 expression inhibited the STAT3 signaling pathway, which caused the SKOV3/tax cells to regain paclitaxel sensitivity. The findings of the present study provide a novel potential strategy to overcome the chemoresistance challenge in the clinical treatment of ovarian cancer in patients.

\section{Acknowledgements}

Not applicable.

\section{Funding}

The present study was funded by the National Natural Science Foundation of China (grant no. 31670821).

\section{Availability of data and materials}

All data generated or analyzed during this study are included in this published article.

\section{Authors' contributions}

YG and SL conceived and designed the experiments. SL performed the majority of the experiments, XZ, SC, YL and MG performed some of the experiments. SL and YG wrote the manuscript. All authors reviewed the manuscript.

\section{Ethics approval and consent to participate}

Not applicable.

\section{Patient consent for publication}

Not applicable.

\section{Competing interests}

The authors declare that they have no competing interests.

\section{References}

1. Gloss BS and Samimi G: Epigenetic biomarkers in epithelial ovarian cancer. Cancer Lett 342: 257-263, 2014.

2. Sundar S, Wu J, Hillaby K, Yap J and Lilford R: A systematic review evaluating the relationship between progression free survival and post progression survival in advanced ovarian cancer. Gynecol Oncol 125: 493-499, 2012.

3. Ziebarth AJ, Landen CN Jr and Alvarez RD: Molecular/genetic therapies in ovarian cancer: Future opportunities and challenges. Clin Obstet Gynecol 55: 156-172, 2012.

4. Kipps E, Tan DS and Kaye SB: Meeting the challenge of ascites in ovarian cancer: New avenues for therapy and research. Nat Rev Cancer 13: 273-282, 2013.

5. Ford JM, Bruggemann EP, Pastan I, Gottesman MM and Hait WN: Cellular and biochemical characterization of thioxanthenes for reversal of multidrug resistance in human and murine cell lines. Cancer Res 50: 1748-1756, 1990.

6. Ranganathan S, Benetatos CA, Colarusso PJ, Dexter DW and Hudes GR: Altered beta-tubulin isotype expression in paclitaxel-resistant human prostate carcinoma cells. Br J Cancer 77: 562-566, 1998.

7. Hari M, Loganzo F, Annable T, Tan X, Musto S, Morilla DB, Nettles JH, Snyder JP and Greenberger LM: Paclitaxel-resistant cells have a mutation in the paclitaxel-binding region of beta-tubulin (Asp26Glu) and less stable microtubules. Mol Cancer Ther 5: 270-278, 2006.

8. Haass NK, Beaumont KA, Hill DS, Anfosso A, Mrass P, Munoz MA, Kinjyo I and Weninger W: Real-time cell cycle imaging during melanoma growth, invasion, and drug response. Pigment Cell Melanoma Res 27: 764-776, 2014.

9. Kapse-Mistry S, Govender T, Srivastava R and Yergeri M: Nanodrug delivery in reversing multidrug resistance in cancer cells. Front Pharmacol 5: 159, 2014.

10. Bordelon JR and Grichnik JM: TGF- $\beta$ may control the switch between tumorigenic growth and 'stem cell/mesenchymal' potentially drug-resistant states. Dermatol Ther (Heidelb) 28: 177-178, 2015.

11. Bernardini M, Lee $\mathrm{CH}$, Beheshti B, Prasad M, Albert M, Marrano P, Begley H, Shaw P, Covens A, Murphy J, et al: High-resolution mapping of genomic imbalance and identification of gene expression profiles associated with differential chemotherapy response in serous epithelial ovarian cancer. Neoplasia 7: 603-613, 2005.

12. Cicchillitti L, Di Michele M, Urbani A, Ferlini C, Donat MB, Scambia G and Rotilio D: Comparative proteomic analysis of paclitaxel sensitive A2780 epithelial ovarian cancer cell line and its resistant counterpart A2780TC1 by 2D-DIGE: The role of ERp57. J Proteome Res 8: 1902-1912, 2009.

13. Duan Z, Feller AJ, Penson RT, Chabner BA and Seiden MV: Discovery of differentially expressed genes associated with paclitaxel resistance using cDNA array technology: Analysis of interleukin (IL) 6 , IL-8, and monocyte chemotactic protein 1 in the paclitaxel-resistant phenotype. Clin Cancer Res 5: 3445-3453, 1999.

14. Livak KJ and Schmittgen TD: Analysis of relative gene expression data using real-time quantitative PCR and the 2(-Delta Delta C(T)) Method. Methods 25: 402-408, 2001.

15. Szklarczyk D, Morris JH, Cook H, Kuhn M, Wyder S, Simonovic M, Santos A,Doncheva NT, Roth A, Bork P, et al: The STRING database in 2017: Quality-controlled protein-protein association networks, made broadly accessible. Nucleic Acids Res 45D: D362-D368, 2017.

16. Zuberi K, Franz M, Rodriguez H, Montojo J, Lopes CT, Bader GD and Morris Q: GeneMANIA prediction server 2013 update. Nucleic Acids Res 41W: W115-W22, 2013.

17. de Leeuw N, Dijkhuizen T, Hehir-Kwa JY, Carter NP, Feuk L, Firth HV, Kuhn RM, Ledbetter DH, Martin CL, van Ravenswaaij-Arts CM, et al: Diagnostic interpretation of array data using public databases and internet sources. Hum Mutat 33: 930-940, 2012.

18. Huang W, Sherman BT and Lempicki RA: Systematic and integrative analysis of large gene lists using DAVID bioinformatics resources. Nat Protoc 4: 44-57, 2009. 
19. Vikhanskaya F, Erba E, D'Incalci M and Broggini M: Introduction of wild-type $\mathrm{p} 53$ in a human ovarian cancer cell line not expressing endogenous p53. Nucleic Acids Res 22: 1012-1017, 1994.

20. Alaseem A, Alhazzani K, Dondapati P, Alobid S, Bishayee A and Rathinavelu A: Matrix Metalloproteinases: A challenging paradigm of cancer management. Semin Cancer Biol: Nov 16, 2017 (Epub ahead of print).

21. Cicchillitti L, Della Corte A, Di Michele M, Donati MB, Rotilio D and Scambia G: Characterisation of a multimeric protein complex associated with ERp57 within the nucleus in paclitaxel-sensitive and -resistant epithelial ovarian cancer cells: The involvement of specific conformational states of beta-actin. Int J Oncol 37: 445-454, 2010.

22. Haufroid V: Genetic polymorphisms of ATP-binding cassette transporters $\mathrm{ABCB} 1$ and $\mathrm{ABCC} 2$ and their impact on drug disposition. Curr Drug Targets 12: 631-646, 2011.

23. Kwak JO, Lee SH, Lee GS, Kim MS, Ahn YG, Lee JH, Kim SW, Kim KH and Lee MG: Selective inhibition of MDR1 (ABCB1) by HM30181 increases oral bioavailability and therapeutic efficacy of paclitaxel. Eur J Pharmacol 627: 92-98, 2010.

24. Calastretti A, Gatti G, Quaresmini C and Bevilacqua A: Down-modulation of Bcl-2 sensitizes PTEN-mutated prostate cancer cells to starvation and taxanes. Prostate 74: 1411-1422, 2014.

25. Luo Y, Tong L, Meng H, Zhu W, Guo L, Wei T and Zhang J: MiR-335 regulates the chemo-radioresistance of small cell lung cancer cells by targeting PARP-1. Gene 600: 9-15, 2017.

26. Friedrich K, Wieder T, Von Haefen C, Radetzki S, Jänicke R, Schulze-Osthoff K, Dörken B and Daniel PT: Overexpression of caspase-3 restores sensitivity for drug-induced apoptosis in breast cancer cell lines with acquired drug resistance. Oncogene 20: 2749-2760, 2001.

27. Turano C, Gaucci E, Grillo C and Chichiarelli S: ERp57/GRP58: A protein with multiple functions. Cell Mol Biol Lett 16: 539-563, 2011.

28. Khanal RC and Nemere I: The ERp57/GRp58/1,25D3-MARRS receptor: Multiple functional roles in diverse cell systems. Curr Med Chem 14: 1087-1093, 2007.

29. Vigneron N, Peaper DR, Leonhardt RM and Cresswell P: Functional significance of tapasin membrane association and disulfide linkage to ERp57 in MHC class I presentation. Eur J Immunol 39: 2371-2376, 2009.

30. Chapman DC and Williams DB: ER quality control in the biogenesis of MHC class I molecules. Semin Cell Dev Biol 21: $512-519,2010$.

31. Frenkel Z, Shenkman M, Kondratyev M and Lederkremer GZ: Separate roles and different routing of calnexin and ERp57 in endoplasmic reticulum quality control revealed by interactions with asialoglycoprotein receptor chains. Mol Biol Cell 15: 2133-2142, 2004.

32. Celli CM and Jaiswal AK: Role of GRP58 in mitomycin C-induced DNA cross-linking. Cancer Res 63: 6016-6025, 2003

33. He Y, Shao F, Pi W, Shi C, Chen Y, Gong D, Wang B, Cao Z and Tang K: Largescale transcriptomics analysis suggests over-expression of BGH3, MMP9 and PDIA3 in oral squamous vell carcinoma. PLoS One 11: e0146530, 2016.

34. Lovat PE, Corazzari M, Armstrong JL, Martin S, Pagliarini V, Hill D, Brown AM, Piacentini M, Birch-Machin MA and Redfern CP: Increasing melanoma cell death using inhibitors of protein disulfide isomerases to abrogate survival responses to endoplasmic reticulum stress. Cancer Res 68: 5363-5369, 2008.

35. Corazzari M, Lovat PE, Armstrong JL, Fimia GM, Hill DS, Birch-Machin M, Redfern CP and Piacentini M: Targeting homeostatic mechanisms of endoplasmic reticulum stress to increase susceptibility of cancer cells to fenretinide-induced apoptosis: The role of stress proteins ERdj5 and ERp57. Br J Cancer 96: 1062-1071, 2007.

36. Choe MH, Min JW, Jeon HB, Cho DH, Oh JS, Lee HG, Hwang SG, An S, Han YH and Kim JS: ERp57 modulates STAT3 activity in radioresistant laryngeal cancer cells and serves as a prognostic marker for laryngeal cancer. Oncotarget 6: 2654-2666, 2015.

37. Bourougaa K, Naski N,Boularan C, Mlynarczyk C, Candeias MM, Marullo S and Fåhraeus R: Endoplasmic reticulum stress induces $\mathrm{G} 2$ cell-cycle arrest via mRNA translation of the p53 isoform p53/47. Mol Cell 38: 78-88, 2010.
38. Candeias MM, Powell DJ, Roubalova E, Apcher S, Bourougaa K, Vojtesek B, Bruzzoni-Giovanelli H and Fåhraeus R: Expression of p53 and p53/47 are controlled by alternative mechanisms of messenger RNA translation initiation. Oncogene 25: 6936-6947, 2006.

39. Carpenter RL and Lo HW: STAT3 target genes relevant to human cancers. Cancers (Basel) 6: 897-925, 2014.

40. Guo GG, Patel K, Kumar V, Shah M, Fried VA, Etlinger JD and Sehgal PB: Association of the chaperone glucose-regulated protein 58 (GRP58/ER-60/ERp57) with Stat3 in cytosol and plasma membrane complexes. J Interferon Cytokine Res 22: 555-563, 2002.

41. Chichiarelli S, Gaucci E, Ferraro A, Grillo C, Altieri F, Cocchiola R, Arcangeli V, Turano C and Eufemi M: Role of ERp57 in the signaling and transcriptional activity of STAT3 in a melanoma cell line. Arch Biochem Biophys 494: 178-183, 2010.

42. Eufemi M, Coppari S, Altieri F, Grillo C, Ferraro A and Turano C: ERp57 is present in STAT3-DNA complexes. Biochem Biophys Res Commun 323: 1306-1312, 2004.

43. Gu F, Ma Y, Zhang Z, Zhao J, Kobayashi H, Zhang L and Fu L: Expression of Stat 3 and Notch1 is associated with cisplatin resistance in head and neck squamous cell carcinoma. Oncol Rep 23: 671-676, 2010.

44. Zhu H, Chen X, Chen B, Chen B, Fan J, Song W, Xie Z, Jiang D, Li Q, Zhou M, et al: Activating transcription factor 4 mediates a multidrug resistance phenotype of esophageal squamous cell carcinoma cells through transactivation of STAT3 expression. Cancer Lett 354: 142-152, 2014.

45. Ryu K, Susa M, Choy E, Yang C, Hornicek FJ, Mankin HJ and Duan Z: Oleanane triterpenoid CDDO-Me induces apoptosis in multidrug resistant osteosarcoma cells through inhibition of Stat3 pathway. BMC Cancer 10: 187, 2010.

46. Gariboldi MB, Ravizza R, Molteni R, Osella D, Gabano E and Monti E: Inhibition of Stat 3 increases doxorubicin sensitivity in a human metastatic breast cancer cell line. Cancer Lett 258: 181-188, 2007.

47. Selvendiran K, Bratasz A, Kuppusamy ML, Tazi MF, Rivera BK and Kuppusamy P: Hypoxia induces chemoresistance in ovarian cancer cells by activation of signal transducer and activator of transcription 3. Int J Cancer 125: 2198-2204, 2009.

48. Zhang F, Wang Z, Fan Y, Xu Q, Ji W, Tian R and Niu R: Elevated STAT3 signaling-mediated upregulation of MMP-2/9 confers enhanced invasion ability in multidrug-resistant breast cancer cells. Int J Mol Sci 16: 24772-24790, 2015.

49. Yang JM, Xu Z, Wu H,Zhu H,Wu X and Hait WN: Overexpression of extracellular matrix metalloproteinase inducer in multidrug resistant cancer cells. Mol Cancer Res 1: 420-427, 2003.

50. Colone M, Calcabrini A, Toccacieli L, Bozzuto G, Stringaro A, Gentile M, Cianfriglia M, Ciervo A, Caraglia M, Budillon A, et al: The multidrug transporter P-glycoprotein: A mediator of melanoma invasion? J Invest Dermatol 128: 957-971, 2008.

51. Hikawa T, Mori T, Abe T and Hori S: The ability in adhesion and invasion of drug-resistant human glioma cells. Journal of experimental and clinical cancer research. CR (East Lansing Mich) 19: 357-362, 2000.

52. Işeri OD, Kars MD, Arpaci F and Gündüz U: Gene expression analysis of drug-resistant MCF-7 cells: Implications for relation to extracellular matrix proteins. Cancer Chemother Pharmacol 65: 447-455, 2010.

53. Santana-Codina N, Carretero R, Sanz-Pamplona R, Cabrera T, Guney E, Oliva B, Clezardin P, Olarte OE, Loza-Alvarez P, Méndez-Lucas A, et al: A transcriptome-proteome integrated network identifies endoplasmic reticulum thiol oxidoreductase (ERp57) as a hub that mediates bone metastasis. Mol Cell Proteomics 12: 2111-2125, 2013.

54. Xu D, Perez RE, Rezaiekhaligh MH, Bourdi M and Truog WE: Knockdown of ERp57 increases BiP/GRP78 induction and protects against hyperoxia and tunicamycin-induced apoptosis. Am J Physiol Lung Cell Mol Physiol 297: L44-L51, 2009.

55. Zhao G, Lu H and Li C: Proapoptotic activities of protein disulfide isomerase (PDI) and PDIA3 protein, a role of the Bcl-2 protein Bak. J Biol Chem 290: 8949-8963, 2015. 